Altai State University

Acta Biologica Gibirica

Journal of Biology

Founded in 2015 www.asu.ru

ISSN 2412-1908

Acta Biologica Sibirica, 2017, 3(3), 71-75

UDC 582.261.1

\title{
Morphogenesis of the taxonomically significant microstructures of the siliceous cell wall of the diatom Aulacoseira granulata
}

\author{
Ye.D. Bedoshvili, K.V. Gneusheva, Ye.V. Likhoshway \\ Limnological Institute of the Siberian Branch \\ of the Russian Academy of Sciences, Irkutsk, Russian Federation \\ bedoshvilied@list.ru, kani161089@rambler.ru, likhoshway@mail.ru
}

\begin{abstract}
This paper documents the process of the siliceous valve formation in diatom Aulacoseira granulata from Bratsk Reservoir (Irkutsk Region, Russia) reveals by scanning electron microscopy. It is shown that the shape of separating spines that facilitate colony splitting and species dispersal, as well as that of mucus-producing labiate processes, is determined during the early stages of the morphogenesis.

Key words: centric diatoms; siliceous cell wall; microstructures; morphogenesis
\end{abstract}

\section{Морфогенез таксономически значимых микроструктур кремнеземного панциря диатомовой водоросли Aulacoseira granulata}

\author{
Е.Д. Бедошвили, К.В. Гнеушева, Е.В. Лихошвай \\ Лимнологический институт Сибирского отделения Российской академии наук, \\ Иркутск, Российская Федерачия \\ bedoshvilied@list.ru, kani161089@ rambler.ru, likhoshway@mail.ru
}

\footnotetext{
В статье по данным сканирующей электронной микроскопии описан процесс формирования кремнеземных створок диатомовой водоросли Aulacoseira granulata из природной популяции Братского водохранилища (Иркутская область, Россия). Показано, что форма разделительных шипов, способствующих разделению колоний, и расселению вида, а также двугубых выростов, функцией которых является выделение слизи, определяется на начальных стадиях морфогенеза

Ключевые слова: центрические диатомовые водоросли; кремнеземный панцирь; микроструктуры; морфогенез
} 
Bedoshvili, Ye.D., et al. (2017). Morphogenesis of the taxonomically.... Acta Biologica Sibirica, 2017, 3(3), 71-75

\section{Введение}

Диатомовые водоросли - одноклеточные автотрофные одноклеточные эукариоты, клеточная стенка которых представлена двустворчатым панцирем из биогенного кремнезема, состоящим из створок и поясковых ободков. Как и весь панцирь, так и каждая его половина - створка - имеют особую структуру, которая лежит в основе таксономии этой группы организмов (Round et al., 1990). Центрические диатомеи имеют радиальную симметрию створок, к ним относится и род Aulacoseira Thw. Створки видов этого рода представляют собой цилиндр, закрытый с одной стороны лицевой частью створки, два таких цилиндра закрывают клетку с двух концов, плотно смыкаясь открытыми частями, по типу капсулы для лекарств. Посредством разных отверстий, выростов и других структур эти одноклеточные организмы осуществляет связь с внешней водной средой и регулирует свое поведение в ней при изменении условий. У видов Aulacoseira это:

- ареолы - отверстия в клеточной стенке, закрытые велумом разнообразной структуры (Crawford \& Likhoshway, 2002).

- двугубые выросты - полые трубки, сплюснутые на внутренней стороне створки и открывающиеся наружу отверстием для выделения слизи; бывают разной формы (Likhoshway, Crawford, 2001);

- и шипы. Aulacoseira - колониальные организмы, соединительные шипы служат для скрепления отдельных клеток между собой в цепочку, или нить, а разделительные - для разрыва этой цепочки; бывают разной формы (Siver, Kling, 1997; Houk, 2003).

Перечисленные структуры - их качественные и количественные признаки лежат в основе диагнозов видов рода и выявляются в полной мере только с помощью сканирующей электронной микроскопии (Сэм). Цель настоящей работы - выяснить с помощью СЭМ, на каких стадиях морфогенеза створок детерминируются ареолы, двугубые выросты и закладывается форма шипов, то есть определяется соединительные они будут или разделительные. Для исследований выбран планктонный вид Aulacoseira granulata (Ehr.) Sim. Этот вид интересен тем, что имеет сетчатый велум, развитую форму двугубого выроста - на длинной изогнутым стебле и отличительную форму соединительных и разделительных шипов (Popovskaya et al., 2016, pls 44-45). Известно, что A. granulata имеет соединительные шипы треугольной формы, плотно скрепляющие клетки между собой, и образует длинные разделительные шипы конической формы, которые приводят к разделению колоний на более короткие, что способствует расселению вида (Davey, Crawford, 1986). Этот вид широко расселен по пресноводным водоемам мира, его геограяя охватывает пять континентов (см. http://www.algaebase.org/search/species/detail/?species_id=30965).

\section{Материалы и методы исследований}

Пробы были отобраны сетью Джеди в августе 2009 г. во время массового цветения Aulacoseira granulata в Братском водохранилище в районе переправы Харанжино «Кантин» (Широта: 55 48' 98" Долгота: 101 68' 59") и зафиксированы 70\% этанолом.

Для исследования створок клетки были обработаны по методике, описанной ранеe (Kharitonenko et al., 2015) и исследованы с помощью сканирующего электронного микроскопа Quanta 200 (FEI, CША).

\section{Результаты}

На рисунке 1 представлены фрагмент колонии, покрытый поясковыми ободками (рис. 1А), и отдельные зрелые створки с разделительными (рис. 1Б) и соединительными (рис. 1В) шипами. Ареолы закрыты велумами с очень мелкими гранулами (рис. 1Г). На рисунке 1Г представлен также фрагмент пояскового ободка с упорядоченными рядами пор.

Развитие шипов происходит на протяжении всего морфогенеза створки - на рисунке 2А и Б видно, что несмотря на наличие длинного паза, все разделительные шипы еще короткие, почти одинаковой длины. Ареолы на лицевой части разделительных створок зарастают кремнеземом, когда разделительные шипы еще не достигли своей окончательной длины (рис. 2А, Б). На лицевой части соединительных створок ареолы также сохраняются по всей площади поверхности вплоть до формирования шейки (рис. 2В, Г).

На рисунке 3 показаны последовательные стадии формирования ареол. Образование отверстий ареол происходит одновременно с формированием загиба створки, сначала образуются продольные тяжи, которые потом соединяются в сеть поперечными перемычками (рис. ЗА). После этого происходит утолщение створки (рис. 3Б) и рост разделительных шипов (в случае формирования разделительной створки). Гранулы на створке, характерные для исследуемого вида, хорошо видны еще до начала формирования велума (рис. 2А, 3Б). Велум начинают формироваться в виде мелких ответвлений от стенок ареол (рис. ЗВ), после этого растущие ответвления образуют кольцо вокруг центра ареолы (рис. ЗГ) и также образуют ветвления (рис. ЗД). После этого на велуме образуется характерный для зрелых створок (рис. 1Г) слой мелких гранул (рис. ЗЕ). 
Bedoshvili, Ye.D., et al. (2017). Morphogenesis of the taxonomically.... Acta Biologica Sibirica, 2017, 3(3), 71-75

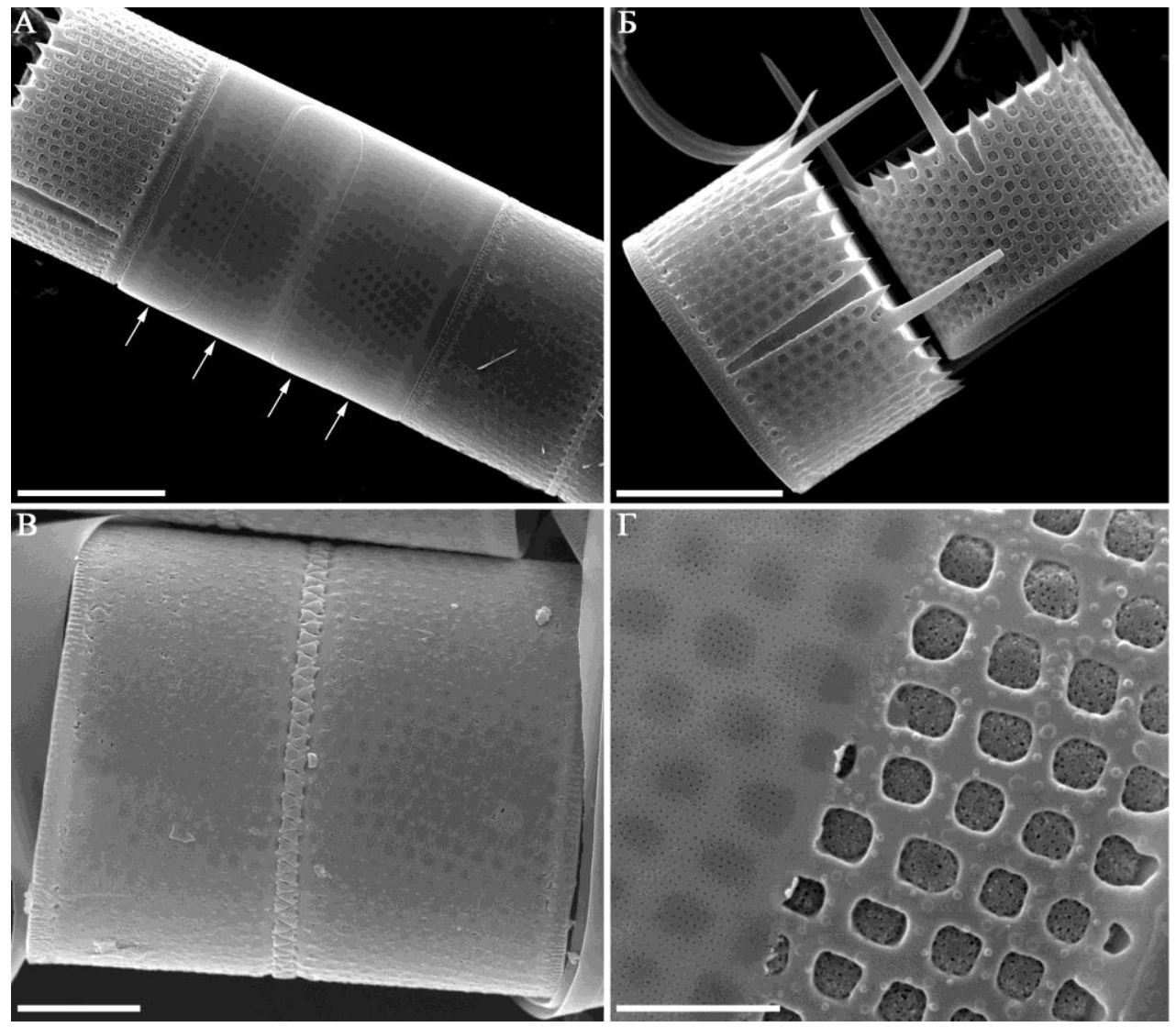

Рис. 1. Зрелые створки Aulacoseira granulata (СЭМ).

А - колония клеток, соединенных соединительными шипами, часть клеток прикрыта поясковыми ободками (стрелки); Б - разделительные створки; В - соединительные створки двух соседних клеток; Г - ареолы зрелой створки и фрагмент пояскового ободка (видны многочисленные поры). Масштаб: А, Б - 10 мкм; В - 5 мкм; Г - 2 MKM.

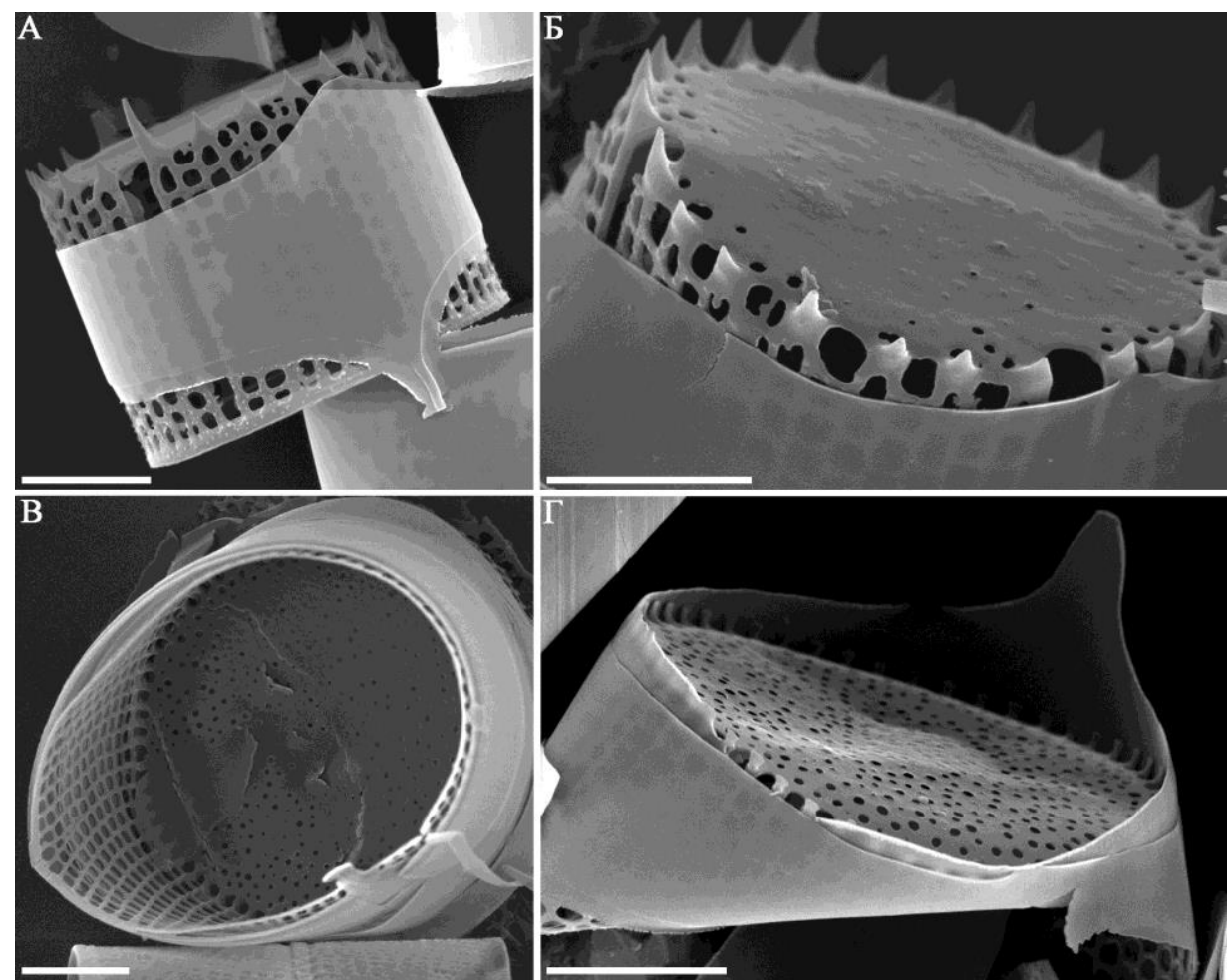

Рис. 2. Разделительные (A, Б) и соединительные (B, Г) створки на стадии дифференцирования ареол.

А - загиб разделительной створки, прикрытый поясковым ободком; Б - лицевая часть разделительной створки; В - соединительная створка, вид изнутри; Г - лицевая часть соединительной створки. Масштаб - 5 мкм. 
Bedoshvili, Ye.D., et al. (2017). Morphogenesis of the taxonomically.... Acta Biologica Sibirica, 2017, 3(3), 71-75

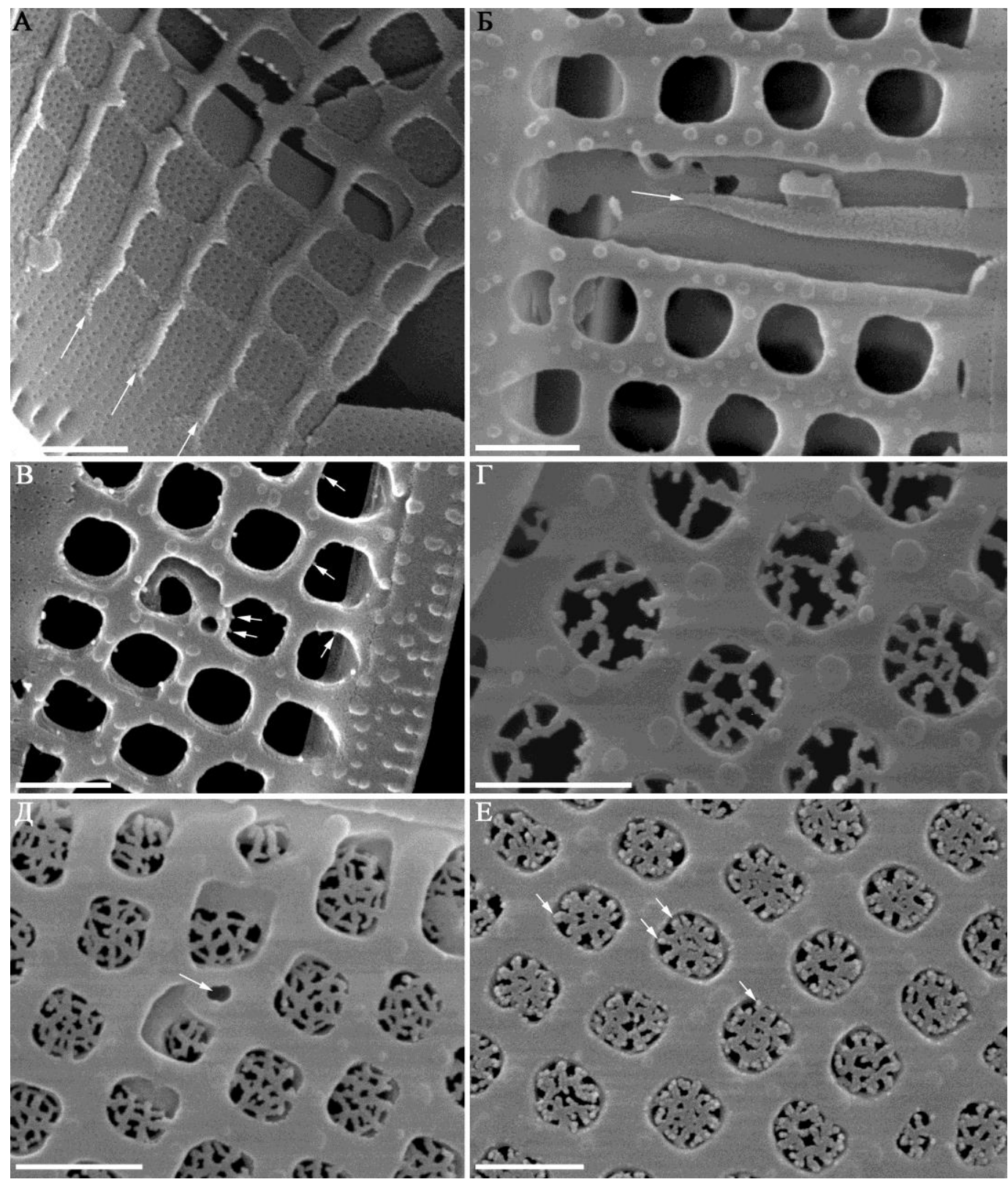

Рис. 3. Ареолы и двугубые выросты на разных стадиях формирования.

А - формирование загиба створки (продольные тяжи показаны стрелкой); Б - рост разделительного шипа (стрелка); В - двугубый вырост на загибе створки и начало формирования крибрумов (стрелки - зачатки крибрумов); Г - рост крибрумов; Д - завершение морфогенеза крибрумов (стрелка - отверстие двугубого выроста); Е - образование мелких гранул на крибрумах (стрелки). Масштаб - 1 мкм.

\section{Обсуждение}

Характеризуя природную популяцию A. granulata авторы (Davey, Crawford, 1986) ввели в свое время новое понятие - индекс разделительных створок (separation valve index, SVI), характеризующий готовность колоний в популяции к разделению и расселению. Для другого вида этого рода, A. baicalensis нами было показано, что SVI меняется в течение года и достигает наибольших значений в конце весны, когда в результате активной вегетации плотность популяции вида достигает максимальных величин (Bedoshvili et al., 2007). Позже для A. baicalensis было показано, что развитие шипов опережает формирование других структур (Bedoshvili et al., 2012). Данные, полученные в настоящем исследовании, подтверждают предположение о том, что форма шипов (разделительные или соединительные) определяется на самых ранних стадиях в начале морфогенеза створки.

Помимо секреции слизи, которая может выполнять самые разные функции (защищать клеточную стенку от воздействия бактерий, регулировать плавучесть у планктонных видов и др.), двугубые выросты выполняют и внутриклеточную функцию. Известно, что формирование двугубых выростов находится под контролем особой структуры - аппарата двугубого выроста (LPA, labiate process apparatus; Pickett-Heaps et al., 1988). Цитологические исследования A. granulata ранее не проводились, однако, мы можем предположить, что у этого вида в клетках имеются две такие структуры (по числу двугубых выростов), активные на протяжении всего процесса морфогенеза створки. Одной дополнительных функций аппарата двугубого выроста может быть центр нуклеации 
Bedoshvili, Ye.D., et al. (2017). Morphogenesis of the taxonomically.... Acta Biologica Sibirica, 2017, 3(3), 71-75

микротрубочек. Длинный и закрученный двугубый вырост может давать виду A. granulata дополнительные преимущества, сформированные в процессе эволюции. Интересно, что форма двугубого выроста у A. baicalensis, в отличие от $A$. granulata, принимает свою окончательную форму только когда формирование велумов уже заканчивается (Bedoshvili et al., 2012, fig. 4D, F). Этот факт может говорить о различной временной программе жизненных циклов и о различиях в функционировании аппарата двугубого выроста у этих видов.

Полученные данные позволяют считать, что ранняя закладка исследованных элементов панциря подчеркивает их функциональную важность, при этом, одноклеточный организм сразу после цитокинеза, когда начинают формироваться новые створки в дочерних клетках, запускает реализацию программы, важной для поведения вида, в частности - оставаться в данных условиях обитания или расселяться.

\section{Благодарности}

Работа выполнена в рамках проекта ФАНО № 0345-2014-0001 «Исследования эволюционных, экологических и молекулярно-биологических аспектов кремний-зависимых хромист как основных участников круговорота кремния в водных экосистемах» на приборах ЦКП «Электронная микроскопия» ОЦКП «Ультрамикроанализ» ЛИН CO PAH.

\section{References}

Bedoshvili, Ye., Kaluzhnaya, O., Likhoshway, Ye. (2012). The frustule morphogenesis of Aulacoseira baicalensis in the natural population. Journal of Advanced Microscopy Research, 7, 218-224.

Bedoshvili, Ye.D., Bondarenko, N.A., Sakirko, M.V., Likhoshway, Ye.V. (2007). The change of the length of colonies of planktonic diatom Aulacoseira baicalensis in various stages of the annual cycle in Lake Baikal. Hydrobiological Journal, 43, 79-86 (in Russian).

Crawford, R. M., Likhoshway, Y. (2002). The velum of species of the diatom genus Aulacoseira Thwaites. J. John (Ed.). Proceedings of the 15th International Diatom Symposium, Perth, Australia, 1998, Konigstein: Koeltz Scientific Books, 275287.

Davey, M.C., Crawford, R.M. (1986). Filament formation in the diatom Melosira granulata. Journal of Phycology, 22, 144150.

Houk, V. (2003). Atlas of freshwater centric diatoms with a brief key and descriptions. Czech Republic: Palacky University Press.

Kharitonenko, K.V., Bedoshvili, Ye.D., Likhoshway, Ye.V. (2015). Changes in the micro- and nanostructure of siliceous valves in the diatom Synedra acus under the effect of colchicine treatment at different stages of the cell cycle. J. Struct. Res., 190, 73-80.

Likhoshway, Ye., Crawford, R. (2001). The rimoportula - a neglected feature in the systematics of Aulacoseira. A. Economou-Amilli (Ed.). Proceedings of $16^{\text {th }}$ International Diatom Symposium, Athens Aegean Islands: University of Athens, 33-47.

Pickett-Heaps, J.D., Wetherbee, R., Hill, D.R. (1988). Cell division and morphogenesis of the labiate process in the centric diatom Ditylum brightwellii. Protoplasma, 143, 139-149.

Popovskaya, G.I., Genkal, S.I., Likhoshway, Ye.V. (2016). Diatoms of the Plankton of Lake Baikal: Atlas and Key. Novosibirsk: Nauka.

Round, F.E., Crawford, R.M., Mann, D.G. (1990). The Diatoms. Biology and Morphology of the Genera. Cambridge: Cambridge University Press.

Siver, P.A., Kling, H. (1997). Morphological observations of Aulacoseira using scanning electron microscopy. Canadian Journal of Botany, 75, 1807-1835.

\section{Citation:}

Bedoshvili, Ye.D., Gneusheva, K.V., Likhoshway, Ye.V. (2017). Morphogenesis of the taxonomically significant microstructures of the siliceous cell wall of the diatom Aulacoseira granulata. Acta Biologica Sibirica, 3 (3), 71-75.

Submitted:14.07.2016. Accepted: 21.09.2017

cross ref http://dx.doi.org/10.14258/abs.v3i3.3618

(C) 2017 by the authors. Submitted for possible open access publication under the terms and conditions of the Creative Commons Attribution (CC BY) license (http://creativecommons.org/licenses/by/4.0/). 